\title{
WEB ORIENTED APPLICATIONS GENERATOR DEVELOPMENT THROUGH REENGINEERING PROCESS
}

\author{
RADOSEVIC, D.; OREHOVACKI, T. \& KONECKI, M.
}

Abstract: Development of scripting model based generators is re-engineering process, which consists of several phases: making application prototype, defining specification elements and code templates (metaprograms) through separation of concerns, making generator scripting model and generator implementation through generative objects using appropriate $C++$ library. That process corresponds to Barry Boehm spiral model of software development. Main benefits of that approach are flexibility in generator development and easier maintenance of generators and generated applications. Most suitable applications for generating by scripting model based generators are web applications.

Key words: generative programming, generative objects, software reengineering
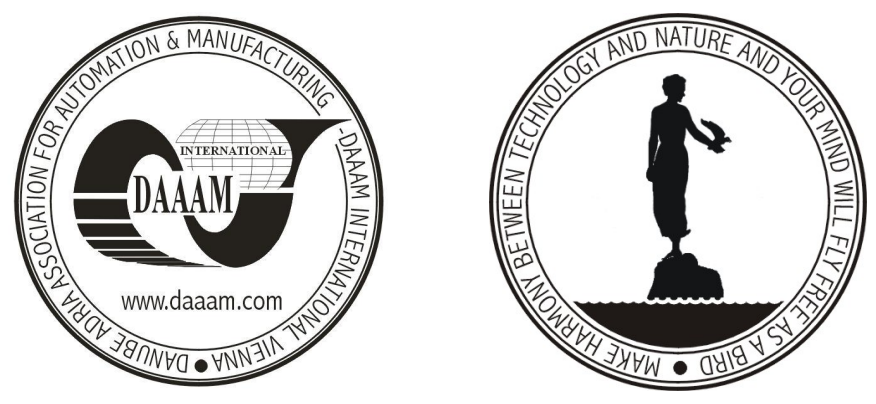

Authors' data: PhD. Radosevic, D[anijel]; BSc. Orehovacki, T[ihomir]; BSc. Konecki, M[ario], Faculty of organization and informatics, University of Zagreb, Pavlinska 2, Varaždin, Croatia, danijel.radosevic@foi.hr, tihomir.orehovacki@foi.hr mario.konecki@foi.hr

This Publication has to be referred as: Radosevic, D.; Orehovacki, T. \& Konecki, M. (2007). Web oriented applications generator development through reengineering process, Chapter 39 in DAAAM International Scientific Book 2007, B. Katalinic (Ed.), Published by DAAAM International, ISBN 3-901509-60-7, ISSN 1726-9687, Vienna, Austria

DOI: $10.2507 /$ daaam.scibook.2007.39 